\title{
Genotype by environment interaction for female fertility traits under conventional and organic production systems in Danish Holsteins
}

\author{
A. Liu, ${ }^{1,2 *}$ G. Su, ${ }^{1}$ J. Höglund, ${ }^{1}$ Z. Zhang, ${ }^{1,3}$ J. Thomasen, ${ }^{1,4} \mathrm{I}$. Christiansen, ${ }^{1,5} \mathrm{Y}$. Wang, ${ }^{2}$ and M. Kargo ${ }^{1,6}$ \\ ${ }^{1}$ Department of Molecular Biology and Genetics, Aarhus University, 8830, Tjele, Denmark \\ ${ }^{2}$ College of Animal Science and Technology, China Agricultural University, 100193, Beijing, China \\ ${ }^{3}$ School of Agriculture and Biology, Department of Animal Science, Shanghai Jiao Tong University, 200240, Shanghai, China \\ ${ }^{4}$ Viking Genetics, Ebeltoftvej 16, 8960, Assentoft, Denmark \\ ${ }^{5}$ Organic Denmark, Silkeborgvej 260, 8230, Aarhus, Denmark \\ ${ }^{6}$ SEGES, Agro Food Park 15, 8200, Aarhus, Denmark
}

\section{ABSTRACT}

Conventional and organic production systems mainly differ in feeding strategies, outdoor and pasture access, and the use of antibiotic treatments. These environmental differences could lead to a genotype by environment interaction $(\mathrm{G} \times \mathrm{E})$ and a requirement for including $\mathrm{G}$ $\times \mathrm{E}$ in breeding decisions. The objectives of this study were to estimate variance components and heritabilities for conventional and organic production systems and investigate $\mathrm{G} \times \mathrm{E}$ under these 2 production systems for female fertility traits in Danish Holsteins. The analyzed traits included the interval from calving to first insemination (ICF), the interval from first to last insemination, number of inseminations per conception (NINS), and non-return rate within $56 \mathrm{~d}$ after the first insemination. Records of female fertility in heifers and the first 3 lactations in cows as well as grass ratio of feed at herd level were collected during the period from 2011 to 2016. The performances of a trait in heifers and cows (lactation 1 to 3 ) were considered as different traits. The (co)variance components and the resulting heritabilities and genetic correlations were estimated using 2 models. One was a bivariate model treating performances of a trait under organic and conventional production systems as 2 different traits using a reduced data set, and the other was a reaction norm model with random regression on the production system and the grass ratio of feed using a full data set. The full data set comprised records of 37,836 females from 112 organic herds and 513,599 females from 1,224 conventional herds, whereas the reduced data set comprised records from all these 112 organic herds and 92,696 females from 185 convention herds extracted from the full data set with grass ratio of feed lower than 0.20. All female fertility performances of the organic production system

Received July 31, 2018.

Accepted April 26, 2019.

*Corresponding author: aoxing.liu@mbg.au.dk were superior to those of the conventional production system. Besides, heterogeneities in additive genetic variances and heritabilities were observed between conventional and organic production systems for all traits. Furthermore, genetic correlations between these 2 production systems ranged from 0.607 to 1.000 estimated from bivariate models and from 0.848 to 0.999 estimated from reaction norm models. Statistically significant $\mathrm{G} \times \mathrm{E}$ were observed for NINS in heifers, non-return rate within $56 \mathrm{~d}$ after the first insemination in heifers, and ICF from the bivariate model, and for ICF and NINS in cows from the reaction norm model. Key words: female fertility, genotype by environment interaction, grass ratio of feed, Holstein, organic farm

\section{INTRODUCTION}

Poor female fertility has been widely observed in highproducing dairy cattle (Veerkamp and Beerda, 2007; Liu et al., 2017), which caused considerable economic losses due to increases of additional inseminations, veterinary treatments and involuntary culling (González-Recio et al., 2004; NAV, 2018). The genetic gain for female fertility achieved by selection is relatively slow, due to the low heritable nature of female fertility and its negative genetic correlation with milk production traits which have been under strong selection. Moreover, the ignorance of possible genotype by environment interaction $(\mathbf{G} \times \mathbf{E})$ could lead to a reduction in genetic gain. The $\mathrm{G} \times \mathrm{E}$ is defined as different genotypes reacting unequally to the changes of environments (Falconer and Mackay, 1996). Nowadays, the issue of $\mathrm{G} \times \mathrm{E}$ in dairy cattle become more crucial than ever before, due to the increasing joint genetic evaluation across countries and the existence of multiple production systems within a country. In the recent across-county genetic evaluation run by Interbull in December 2018, moderate to strong $\mathrm{G} \times \mathrm{E}$ [genetic correlation $\left(r_{g}\right)$ ranged from 0.46 between bulls from Israel and New Zealand to 0.94 between bulls from Netherlands and Germany] were 
observed for lactating cow's ability to conceive across Holstein populations from 20 countries with intensive and extensive production modes (Interbull, 2018). The $\mathrm{G} \times \mathrm{E}$ for female fertility between multiple production systems within a country has also been reported (Sundberg et al., 2010; Calus et al., 2002). A unique production system, however, is usually considered in the routine genetic evaluation.

In Denmark, $87 \%$ of registered milking cows were from the conventional production system, whereas the remaining $13 \%$ registered milking cows were from the organic production system (Lauridsen, 2018). The organic production system is expected to be further enlarged in the future due to customers' increased attention to the quality, health, and environmental friendliness of dairy products (Rosati and Aumaitre, 2004; Thøgersen et al., 2017). Compared with the conventional production system, the organic production system has more stringent rules for feeding strategies, outdoor and pasture access, and the use of antibiotic treatments (Bennedsgaard et al., 2003; Rosati and Aumaitre, 2004; Von Borell and Sørensen, 2004). These differences between conventional and organic production systems could lead to $\mathrm{G} \times \mathrm{E}$ (Boelling et al., 2003), especially for low heritable traits such as female fertility. However, so far, only a few studies focus on $\mathrm{G} \times \mathrm{E}$ under organic and conventional production systems for female fertility (Pryce et al., 1999; Sundberg et al., 2010). Moreover, $\mathrm{G} \times \mathrm{E}$ for female fertility in heifers has been less reported, although heifer fertility is an essential part of the routine genetic evaluation of female fertility (Kargo et al., 2014).

In the current Danish dairy industry, the breeding bulls used for the organic production system are selected based on data from all herds (Kargo et al., 2018), with the majority being from the conventional production system. The possible $\mathrm{G} \times \mathrm{E}$ between conventional and organic production systems has not yet been considered in the routine genetic evaluation. One possible consequence of $\mathrm{G} \times \mathrm{E}$ is the re-ranking of animals across environments (Falconer and Mackay, 1996), and thus, the best animals selected for one environment may not perform the best in another environment. Therefore, it is beneficial to develop separate breeding programs when moderate to severe $\mathrm{G} \times \mathrm{E}$ exists $\left(r_{g}\right.$ lower than 0.61; Mulder et al., 2006). If moderate to severe $\mathrm{G} \times \mathrm{E}$ in relation to conventional and organic production systems exists in Danish Holsteins, we need to assess the necessity to develop a breeding program that is optimal for both conventional and organic production systems.

To detect the existence and the magnitude of $\mathrm{G} \times \mathrm{E}$, a multivariate model (Falconer and Mackay, 1996) and a reaction norm model (Falconer and Mackay, 1996; Strandberg et al., 2000) are widely used. A multivariate model is usually used when environments are distinctly different between groups of individuals. Thus, performances of a trait under different environments are treated as different traits. In this case, the genetic correlation of traits under different environments is used as the indicator of $\mathrm{G} \times \mathrm{E}$ (Falconer and Mackay, 1996; Sundberg et al., 2010; Ismael et al., 2016). The definition of a reaction norm is the genotype's sensitivity to different environments (Falconer and Mackay, 1996). A reaction norm model is widely used when environments are not extremely distinct and differences of environments can be described by a continuous variable. Although different orders of polynomials can be used in a reaction norm model, generally, a linear reaction norm model was used to detect $\mathrm{G} \times \mathrm{E}$. In a linear reaction norm model, the breeding value of an animal can be partitioned into 2 parts: one part is independent on environments (i.e., intercept of the reaction norm), and the other part is dependent on environments (i.e., slope of the reaction norm; Calus et al., 2002). The intercept and the slope are available for each animal, where the slope indicates the animal's sensitivity to environments. In this case, the variance of the slope is used as the indicator of $\mathrm{G} \times \mathrm{E}$ (Cardoso and Tempelman, 2012; Ismael et al., 2016). To better model G $\times$ E using a reaction norm model, a continuous variable that can adequately describe the changes of environments is essential. Average production levels (Calus et al., 2005; Kargo et al., 2012), herd management (Fikse et al., 2003), and climate changes (Oliveira et al., 2018) were widely used as environmental descriptors for estimation of $\mathrm{G} \times \mathrm{E}$. A reaction norm model with unknown environmental descriptors (e.g., herd-year) implementing a Bayesian method could be used when no appropriate environmental descriptor is available (Su et al., 2006). The feeding level, reflecting the intake energy, has been highly recommended as an environmental descriptor for a reaction norm model (Calus et al., 2002; Fikse et al., 2003; Kolmodin et al., 2002). However, no G $\times$ E study with reaction norm on feeding levels has been performed previously due to difficulties of recording and collecting detailed feeding information on a large scale.

The objectives of this study were to estimate variance components and heritabilities for conventional and organic production systems and investigate $\mathrm{G} \times$ E under these 2 production systems for female fertility traits in Danish Holsteins.

\section{MATERIALS AND METHODS}

\section{Data}

Female Fertility. Female fertility records from AI were collected during the period from 2011 to 2016 for Danish Holsteins from 1,663 conventional herds and 153 
organic herds. The analyzed traits included the interval from calving to first insemination (ICF), the interval from first to last insemination (IFL), number of inseminations per conception (NINS), and non-return rate within $56 \mathrm{~d}$ after the first insemination (NRR). The NRR was coded as 1 when there was no subsequent insemination within $56 \mathrm{~d}$ after the first insemination and 0 otherwise. The performances of a trait in heifers and cows (lactation 1 to 3 ) were considered as different traits, with $\mathbf{h}$ (for heifers) and $\mathbf{c}$ (for cows) as suffixes in trait abbreviations accordingly. The ICF was available only for cows, and all remaining traits were available for both heifers and cows. Animals changing herds during the data collection period were excluded from analyses. Meanwhile, only data from herds that had more than 30 Holstein cattle within a year were included in analyses. The other criteria used for data editing were similar to those in the Nordic routine genetic evaluation (NAV, 2018): age at first insemination in the range from 270 to $900 \mathrm{~d}$, age at first calving in the range from 500 to $1,100 \mathrm{~d}$, ICF in the range from 20 to $230 \mathrm{~d}$; days open in the range from 20 to $365 \mathrm{~d}$, gestation length greater than $260 \mathrm{~d}$, IFL less than $365 \mathrm{~d}$, and NINS less than 5 . Records with values below the lower limit were set to missing, and records with values above the upper limit were set as the upper limit.

Grass Ratio of Feed. The official registrations of the production system (conventional vs. organic), and the start and end time of organic management were provided by SEGES (https://www.seges.dk/da-dk) and Organic Denmark (http://organicdenmark.com/about -organic-denmark/about-our-organisation). During the data collection period (from 2011 to 2016), 21 herds were converted from the organic production system to the conventional production system, whereas one herd was converted from the conventional production system to the organic production system. For those herds, only the records before the converting time were included in analyses, and those records were considered as being from the production system before the converting. By using this method, influences of converting from one production system to another production system were avoided. Grass ratio of feed, defined as the ratio of grass to the total amount of feed (consisting of both grass, other forages, and concentrates), was provided by the cattle database for each herd. The grass consisted of the following feedstuffs: pasture grass, fresh grass, grass silage, hay, artificial dried grass, and alfalfa. Seasons related to grass ratio of feed were defined as summer (April 15 to November 1) and winter (November 2 to April 14). Generally, organic herds tend to have a higher grass ratio of feed than conventional herds. The average grass ratio of feed was 0.58 in summer and 0.50 in winter for organic herds, whereas the ratio was 0.27 in summer and 0.26 in winter for conventional herds. Differences in grass ratio of feed between summer and winter varied largely across herds. Therefore, we only kept the herds with grass ratio of feed recorded in both seasons. For each herd, the final grass ratio of feed was calculated as the average over summer and winter. The distribution of grass ratio of feed for conventional and organic herds are presented in Figure 1.

\section{Model}

A bivariate model and a reaction norm model were used to estimate (co)variance components and the resulting heritabilities and genetic correlations under conventional and organic production systems. Accordingly, 2 data sets were used in analyses: a full data set for the reaction norm model and a reduced data set for the bivariate model. After quality control, a full data set included records of 513,599 females from 1,224 conventional herds and 37,836 females from 112 organic herds. A reduced data set was extracted from the full data set based on the grass ratio of feed, to perform an investigation of $\mathrm{G} \times \mathrm{E}$ between conventional and organic production systems with distinct differences. The thresholds of grass ratio of feed for extracting the reduced data set were subjective. In this study, we kept records of 37,836 females from 112 organic herds with grass ratio of feed above 0.38 and 92,696 females from 185 conventional herds with grass ratio of feed below 0.20 as the reduced data set.

Animals with phenotypes were traced 3 generations back to construct pedigrees. Ultimately, the pedigree for the full data set included 1,251,772 females and 14,334 males with birth year from 1991 to 2016; whereas the pedigree for the reduced data set was a subset of the pedigree for the full data set, including 240,634 females and 7,138 males.

Bivariate Model. In a bivariate model, performances of a trait under organic and conventional production systems were considered as 2 different traits. The genetic correlation under organic and conventional production systems was used to indicate the magnitude of $\mathrm{G} \times \mathrm{E}$ (Falconer and Mackay, 1996). The $\mathrm{G} \times \mathrm{E}$ would be statistically significant if the genetic correlation was significantly different from unity by using a one-tailed $t$-test with a significance level at 0.05 (Sundberg et al., 2010; Ismael et al., 2016). In this study, an animal was from either a conventional production system or an organic production system. The genetic connectedness between 2 production systems came from the common sires. A total of 4,271 sires and 1,774 sires were used in conventional and organic production systems separately, with 1,636 sires in common. Average numbers of daughters per sire were 120.3 in the 
conventional production system and 21.3 in the organic production system.

For heifer traits (NRRh, NINSh, and IFLh), the following model was used:

$$
\left[\begin{array}{l}
\mathbf{y}_{1} \\
\mathbf{y}_{2}
\end{array}\right]=\left[\begin{array}{cc}
\mathbf{X}_{1} & \mathbf{0} \\
\mathbf{0} & \mathbf{X}_{2}
\end{array}\right]\left[\begin{array}{c}
\boldsymbol{\beta}_{1} \\
\boldsymbol{\beta}_{2}
\end{array}\right]+\left[\begin{array}{cc}
\mathbf{Z}_{\mathrm{a}_{1}} & \mathbf{0} \\
\mathbf{0} & \mathbf{Z}_{\mathbf{a}_{2}}
\end{array}\right]\left[\begin{array}{c}
\mathbf{a}_{1} \\
\mathbf{a}_{2}
\end{array}\right]+\left[\begin{array}{l}
\mathbf{e}_{1} \\
\mathbf{e}_{2}
\end{array}\right] .
$$

For cow traits (ICF, NRRc, NINSc, and IFLc), the following model was used:

$\left[\begin{array}{l}\mathbf{y}_{1} \\ \mathbf{y}_{2}\end{array}\right]=\left[\begin{array}{cc}\mathbf{X}_{1} & \mathbf{0} \\ \mathbf{0} & \mathbf{X}_{2}\end{array}\right]\left[\begin{array}{c}\boldsymbol{\beta}_{1} \\ \boldsymbol{\beta}_{2}\end{array}\right]+\left[\begin{array}{cc}\mathbf{Z}_{\mathbf{a}_{1}} & \mathbf{0} \\ \mathbf{0} & \mathbf{Z}_{\mathbf{a}_{2}}\end{array}\right]\left[\begin{array}{c}\mathbf{a}_{1} \\ \mathbf{a}_{2}\end{array}\right]+\left[\begin{array}{cc}\mathbf{Z}_{\mathbf{p e}_{1}} & \mathbf{0} \\ \mathbf{0} & \mathbf{Z}_{\mathbf{p e}_{2}}\end{array}\right]\left[\begin{array}{l}\mathbf{p e}_{1} \\ \mathbf{p e}_{2}\end{array}\right]+\left[\begin{array}{l}\mathbf{e}_{1} \\ \mathbf{e}_{2}\end{array}\right]$

where $\mathbf{y}_{i}$ is the vector of observations of the $i$ th production system $(i=1$ representing the organic production system; and $i=2$ representing the conventional production system); $\boldsymbol{\beta}_{i}$ is the vector of fixed effects of the $i$ th production system, including age group (in terms of age at first insemination, divided into age groups of 270 to $419 \mathrm{~d}, 420$ to $444 \mathrm{~d}, 445$ to $469 \mathrm{~d}, 470$ to $500 \mathrm{~d}$, and 500 to $900 \mathrm{~d}$ ), herd-year of birth (for heifer traits) or herd-year of calving (for cow traits), year-month of first insemination within parity (for NRR, NINS, and IFL) or year-month of calving (for ICF), and parity (available only for cow traits); $\mathbf{a}_{i}$ is the vector of additive genetic effects of the $i$ th production system; $\mathbf{p e}_{i}$ is the vector of permanent environmental effects of the $i$ th production system; and $\mathbf{e}_{i}$ is the vector of residual effects of the $i$ th production system. The $\mathbf{X}_{i}, \boldsymbol{Z}_{\mathbf{a}_{i}}$, and $\mathbf{Z}_{\mathbf{p} \mathbf{e}_{i}}$ are the incidence matrices connecting $\boldsymbol{\beta}_{i}, \mathbf{a}_{i}$, and $\mathbf{p e}_{i}$ to $\mathbf{y}_{i}$. It is assumed that $\left[\begin{array}{c}\mathbf{a}_{1} \\ \mathbf{a}_{2}\end{array}\right] \sim N\left(\mathbf{0}, \mathbf{A} \otimes\left[\begin{array}{cc}\sigma_{\mathrm{a}_{1}}^{2} & \sigma_{\mathrm{a}_{1} \mathrm{a}_{2}} \\ & \sigma_{\mathrm{a}_{2}}^{2}\end{array}\right]\right)$, $\left[\begin{array}{l}\mathbf{p e}_{1} \\ \mathbf{p e}_{2}\end{array}\right] \sim N\left(\mathbf{0 , I} \otimes\left[\begin{array}{cc}\sigma_{\mathrm{pe}_{1}}^{2} & 0 \\ & \sigma_{\mathrm{pe}_{2}}^{2}\end{array}\right]\right)$, and $\left[\begin{array}{l}\mathbf{e}_{1} \\ \mathbf{e}_{2}\end{array}\right] \sim N\left(\mathbf{0 , I} \otimes\left[\begin{array}{cc}\sigma_{\mathrm{e}_{1}}^{2} & 0 \\ & \sigma_{\mathrm{e}_{2}}^{2}\end{array}\right]\right)$. In the above distributions, $\mathbf{A}$ is the matrix of additive genetic relationships between individuals in the pedigree, $\mathbf{I}$ is the identity matrix, $\sigma_{a_{i}}^{2}$ is the additive genetic
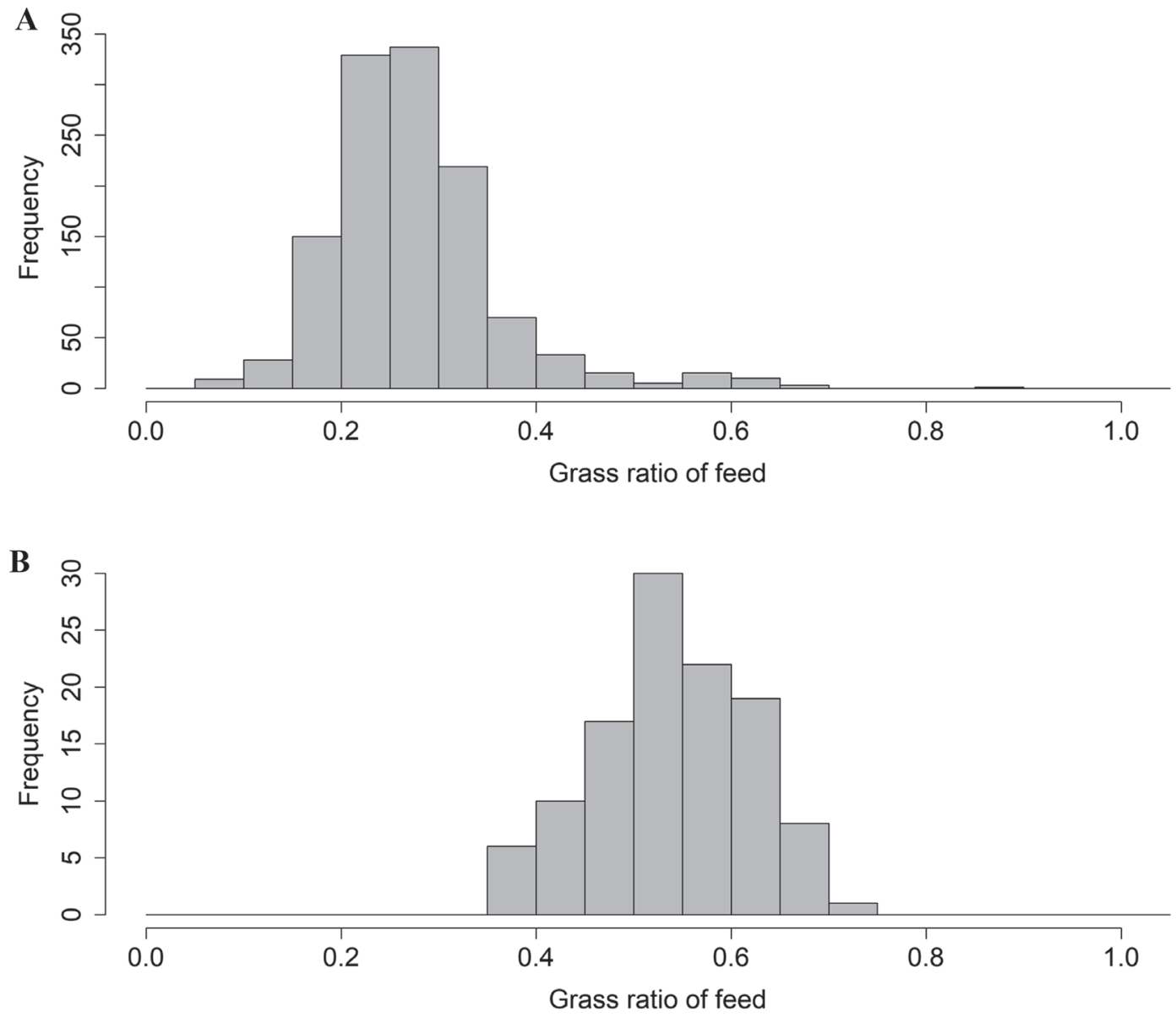

Figure 1. Distribution of grass ratio of feed for conventional (A) and organic (B) production systems in the full data set. 
variance of the $i$ th production system, $\sigma_{a_{1} a_{2}}$ is the additive genetic covariance between organic and conventional production systems, $\sigma_{p e_{i}}^{2}$ is the permanent environmental variance of the $i$ th production system, and $\sigma_{e_{i}}^{2}$ is the residual variance of the $i$ th production system. No permanent environmental covariance and residual covariance existed between 2 production systems, since the animal was raised either in a conventional production system or in an organic production system. The heritability for the $i$ th production system is $h_{i}^{2}=\frac{\sigma_{a_{i}}^{2}}{\sigma_{a_{i}}^{2}+\sigma_{e_{i}}^{2}}$ for heifer traits and $h_{i}^{2}=\frac{\sigma_{a_{i}}^{2}}{\sigma_{a_{i}}^{2}+\sigma_{p e_{i}}^{2}+\sigma_{e_{i}}^{2}}$ for cow traits. The genetic correlation between conventional and organic production systems is $r_{a}=\frac{\sigma_{a_{1} a_{2}}}{\sigma_{a_{1}} \times \sigma_{a_{2}}}$.

Reaction Norm Model. In a reaction norm model, performances of a trait under different environments were treated as the same trait, but breeding values were dependent on environments. A reaction norm model with linear random regressions on the production system and the grass ratio of feed was used. Here, the reaction norm on the grass ratio of feed was used to investigate $\mathrm{G} \times \mathrm{E}$ across any herds with different grass ratio of feed, no matter whether these herds were from a different production system or within the same production system. Beyond the grass ratio of feed, the reaction norm on the production system can account for $\mathrm{G} \times \mathrm{E}$ caused by any environmental differences between organic and conventional production systems rather than the grass ratio of feed (e.g., uses of antibiotic treatments). Thus, the variances of $\mathrm{G} \times \mathrm{E}$ caused by the production system and the grass ratio of feed were partitioned. The $\mathrm{G} \times \mathrm{E}$ would be statistically significant if the variance of the slope was significantly different from zero by using a one-tailed $t$-test with a significance level at 0.05 (Cardoso and Tempelman, 2012; Ismael et al., 2016). Besides, to evaluate whether the goodness of fit improved after including reaction norms for the production system and the grass ratio of feed in the model, the log-likelihood of the reaction norm model was compared with that of a reduced model without these 2 reaction norms. Then, a chi-squared statistic with 5 degrees of freedom was used to test the significance. The degree of freedom was set to 5 because 5 more parameters $\left(\sigma_{\mathrm{a}_{1}}^{2}, \sigma_{\mathrm{a}_{2}}^{2}, \sigma_{\mathrm{a}_{0} \mathrm{a}_{1}}, \sigma_{\mathrm{a}_{0} \mathrm{a}_{2}}\right.$, and $\left.\sigma_{\mathrm{a}_{1} \mathrm{a}_{2}}\right)$ need to be estimated in the reaction norm model compared with the reduced model.

For heifer traits (NRRh, NINSh, and IFLh), the following model was used:

$$
\mathbf{y}=\mathbf{X} \boldsymbol{\beta}+\mathbf{Z}_{0} \mathbf{a}_{0}+\mathbf{Z}_{1} \mathbf{a}_{1}+\mathbf{Z}_{2} \mathbf{a}_{2}+\mathbf{e} .
$$

For cow traits (ICF, NRRc, NINSc, and IFLc), the following model was used:

$$
\mathbf{y}=\mathbf{X} \boldsymbol{\beta}+\mathbf{Z}_{0} \mathbf{a}_{0}+\mathbf{Z}_{1} \mathbf{a}_{1}+\mathbf{Z}_{2} \mathbf{a}_{2}+\mathbf{Z}_{\mathbf{p e}} \mathbf{p e}+\mathbf{e}
$$

where $\mathbf{y}$ is the vector of observations; $\boldsymbol{\beta}$ is the vector of fixed effects, which is the same as the bivariate model; $\mathbf{a}_{0}, \mathbf{a}_{1}$, and $\mathbf{a}_{2}$ are the vectors of additive genetic effects in terms of intercept, random regression coefficient on the production system, and random regression coefficient on the grass ratio of feed, respectively; pe is the vector of permanent environmental effects; and e is the vector of residual effects. For the reaction norm on the production system, we coded the organic production system as 0 and the conventional production system as 1. The reaction norm on a discrete environmental descriptor has also been applied in a previous $\mathrm{G} \times \mathrm{E}$ study for Irish Holsteins (Windig et al., 2011). The $\mathbf{X}$, $\mathbf{Z}_{0}, \mathbf{Z}_{1}, \mathbf{Z}_{2}$, and $\mathbf{Z}_{\mathbf{p e}}$ are the incidence matrices connecting $\boldsymbol{\beta}, \mathbf{a}_{0}, \mathbf{a}_{1}, \mathbf{a}_{2}$, and $\mathbf{p e}$ to $\mathbf{y}$. It is assumed that $\left[\begin{array}{c}\mathbf{a}_{0} \\ \mathbf{a}_{1} \\ \mathbf{a}_{2}\end{array}\right] \sim N\left(\mathbf{0}, \mathbf{A} \otimes\left[\begin{array}{ccc}\sigma_{a_{0}}^{2} & \sigma_{a_{0} a_{1}} & \sigma_{a_{0} a_{2}} \\ \sigma_{a_{0} a_{1}} & \sigma_{a_{1}}^{2} & \sigma_{a_{1} a_{2}} \\ \sigma_{a_{0} a_{2}} & \sigma_{a_{1} a_{2}} & \sigma_{a_{2}}^{2}\end{array}\right]\right), \mathbf{p e} \sim N\left(\mathbf{0}, \mathbf{I} \sigma_{p e}^{2}\right)$, and $\mathbf{e} \sim N\left(\mathbf{0}, \mathbf{I} \sigma_{e}^{2}\right)$. In the above distributions, $\sigma_{a_{0}}^{2}$ is the additive genetic variance for the intercept, $\sigma_{a_{1}}^{2}$ is the additive genetic variance for the regression coefficient on the production system, $\sigma_{a_{2}}^{2}$ is the additive genetic variance for the regression coefficient on the grass ratio of feed, $\sigma_{a_{0} a_{1}}$ is the additive genetic covariance between the intercept and the regression coefficient on the production system, $\sigma_{a_{0} a_{2}}$ is the additive genetic covariance between the intercept and the regression coefficient on the grass ratio of feed, $\sigma_{a_{1} a_{2}}$ is the additive genetic covariance between the regression coefficient on the production system and the regression coefficient on the grass ratio of feed, $\sigma_{p e}^{2}$ is the variance of permanent environmental effects, and $\sigma_{e}^{2}$ is the residual variance. Because each herd had only one level of grass ratio of feed available, the grass ratio of feed was not specified as a fixed effect in the model because the effect was already presented by the herd-year effect. Residual variances were assumed to be the same across herds under different production systems, different levels of grass ratio of feed, or both. The assumption was based on a pilot analysis on 4 subsets varying in grass ratio of feed for each production system (grass ratio of feed $\leq 0.20,0.20$ 
to $0.25,0.25$ to 0.30 , and $\geq 0.30$, respectively, for conventional herds; and grass ratio of feed $\leq 0.50,0.50$ to $0.55,0.55$ to 0.60 , and $\geq 0.60$, respectively, for organic herds), which suggested that the estimates of residual variances for different data sets were similar (results not shown). The total additive genetic variances and the covariance for the performances in an environment of production system level $s_{i}$ with grass ratio of feed level $f_{k}$ and an environment of production system level $s_{j}$ with grass ratio of feed level $l f_{l}$ are

$$
\begin{aligned}
& {\left[\begin{array}{cc}
\sigma_{a \mid s_{i}, f_{k}}^{2} & \sigma_{a\left|s_{i}, f_{k} ; a\right| s_{j}, f_{l}} \\
\sigma_{a\left|s_{i}, f_{k} ; a\right| s_{j}, f_{l}} & \sigma_{a \mid s_{j}, f_{l}}^{2}
\end{array}\right]=} \\
& {\left[\begin{array}{ccc}
1 & s_{i} & f_{k} \\
1 & s_{j} & f_{l}
\end{array}\right]\left[\begin{array}{ccc}
\sigma_{a_{0}}^{2} & \sigma_{a_{0} a_{1}} & \sigma_{a_{0} a_{2}} \\
\sigma_{a_{0} a_{1}} & \sigma_{a_{1}}^{2} & \sigma_{a_{1} a_{2}} \\
\sigma_{a_{0} a_{2}} & \sigma_{a_{1} a_{2}} & \sigma_{a_{2}}^{2}
\end{array}\right]\left[\begin{array}{cc}
1 & 1 \\
s_{i} & s_{j} \\
f_{k} & f_{l}
\end{array}\right] .}
\end{aligned}
$$

The heritability is $h_{\mid s_{i}, f_{k}}^{2}=\frac{\sigma_{a \mid s_{i}, f_{k}}^{2}}{\sigma_{a \mid s_{i}, f_{k}}^{2}+\sigma_{e}^{2}}$ for a heifer trait and $h_{\mid s_{i}, f_{k}}^{2}=\frac{\sigma_{a \mid s_{i}, f_{k}}^{2}}{\sigma_{a \mid s_{i}, f_{k}}^{2}+\sigma_{p e}^{2}+\sigma_{e}^{2}}$ for a cow trait. The genetic correlation is $r_{a\left|s_{i}, f_{k} ; a\right| s_{j}, f_{l}}=\frac{\sigma_{a\left|s_{i}, f_{k} ; a\right| s_{j}, f_{l}}}{\sigma_{a \mid s_{i}, f_{k}} \times \sigma_{a \mid s_{j}, f_{l}}}$.

The (co)variance components for the above models were estimated using the average information REML method implemented in the DMU package (Madsen and Jensen, 2012). The asymptotic standard errors of (co)variance components were obtained from the average information matrix. Standard errors of heritabili- ties and genetic correlations were calculated according to an expansion of the Taylor series (Fischer et al., 2004; Su et al., 2007).

\section{RESULTS}

\section{Descriptive Statistics}

Descriptive statistics for female fertility traits under conventional and organic production systems for the reduced data set and the full data set are presented in Table 1. All female fertility performances in the organic production system were superior to those in the conventional production system. For the conventional production system, the reduced data set was a subset $(\sim 18 \%)$ of the full data set, and thus had similar mean and standard deviation as the full data set. For the organic production system, the reduced data set and the full data set were exactly the same because all organic herds had a grass ratio of feed higher than the threshold (0.38). Besides, correlations between average female fertility performances over herds and grass ratio of feed were negative for NINSh, NINSc, IFLh, and IFLc (ranged from -0.023 for IFLh to -0.166 for NINSc), but positive for ICF, NRRh, and NRRc (ranged from 0.073 for ICF to 0.210 for NRRc). This indicated that herds with higher grass ratio of feed tend to have better female fertility performances for all female fertility traits except for ICF.

\section{Bivariate Model}

For the bivariate model, estimates of (co)variance components and the resulting heritabilities and genetic

\begin{tabular}{|c|c|c|c|c|c|c|c|c|c|}
\hline \multirow[b]{2}{*}{ Trait $^{1}$} & \multirow{2}{*}{$\begin{array}{l}\text { Production } \\
\text { system }\end{array}$} & \multicolumn{2}{|c|}{$\mathrm{N}$} & \multicolumn{2}{|c|}{ Mean } & \multicolumn{2}{|c|}{$\mathrm{SD}$} & \multirow[b]{2}{*}{ Minimum } & \multirow[b]{2}{*}{ Maximum } \\
\hline & & Full & Reduced & Full & Reduced & Full & Reduced & & \\
\hline \multirow[t]{2}{*}{ NINSh } & Conventional & 459,722 & 82,832 & 1.726 & 1.737 & 1.052 & 1.062 & 1 & 5 \\
\hline & Organic & 33,589 & 33,589 & 1.648 & 1.648 & 0.994 & 0.994 & 1 & 5 \\
\hline \multirow[t]{2}{*}{ IFLh } & Conventional & 458,639 & 83,205 & 26.7 & 26.4 & 45.3 & 44.3 & 0 & 230 \\
\hline & Organic & 33,652 & 33,652 & 25.2 & 25.2 & 45.8 & 45.8 & 0 & 230 \\
\hline \multirow[t]{2}{*}{ NRRh } & Conventional & 471,167 & 85,252 & 0.645 & 0.635 & 0.478 & 0.481 & 0 & 1 \\
\hline & Organic & 34,712 & 34,712 & 0.680 & 0.680 & 0.466 & 0.466 & 0 & 1 \\
\hline \multirow[t]{2}{*}{ ICF } & Conventional & 648,884 & 117,606 & 74.1 & 74.0 & 31.0 & 30.3 & 20 & 180 \\
\hline & Organic & 47,986 & 47,986 & 72.8 & 72.8 & 32.2 & 32.2 & 20 & 180 \\
\hline \multirow[t]{2}{*}{ NINSc } & Conventional & 635,571 & 114,947 & 2.090 & 2.138 & 1.254 & 1.282 & 1 & 5 \\
\hline & Organic & 47,049 & 47,049 & 2.061 & 2.061 & 1.242 & 1.242 & 1 & 5 \\
\hline \multirow[t]{2}{*}{ IFLc } & Conventional & 646,573 & 117,127 & 48.7 & 49.5 & 62.1 & 62.3 & 0 & 230 \\
\hline & Organic & 47,804 & 47,804 & 48.1 & 48.1 & 62.4 & 62.4 & 0 & 230 \\
\hline \multirow[t]{2}{*}{ NRRc } & Conventional & 636,303 & 115,056 & 0.536 & 0.518 & 0.499 & 0.500 & 0 & 1 \\
\hline & Organic & 47,112 & 47,112 & 0.556 & 0.556 & 0.497 & 0.497 & 0 & 1 \\
\hline
\end{tabular}

Table 1. Descriptive statistics under conventional and organic production systems for the reduced data set and the full data set

${ }^{1} \mathrm{NINS}=$ number of inseminations per conception; IFL $=$ the interval from first to last insemination; NRR $=$ non-return rate within $56 \mathrm{~d}$ after the first insemination; ICF $=$ the interval from calving to first insemination. For the traits both expressed in heifers and cows, a suffix $\mathrm{h}$ (for heifers) and or c (for cows) was attached to the trait abbreviation. 
Table 2. Variance components, ${ }^{1}$ heritabilities, and genetic correlations $\left(r_{g}\right)$ under conventional and organic production systems from the bivariate model (BM) using the reduced data set, and heritabilities and genetic correlations under average grass ratio of feed ${ }^{2}$ from the reaction norm model (RM) using the full data set

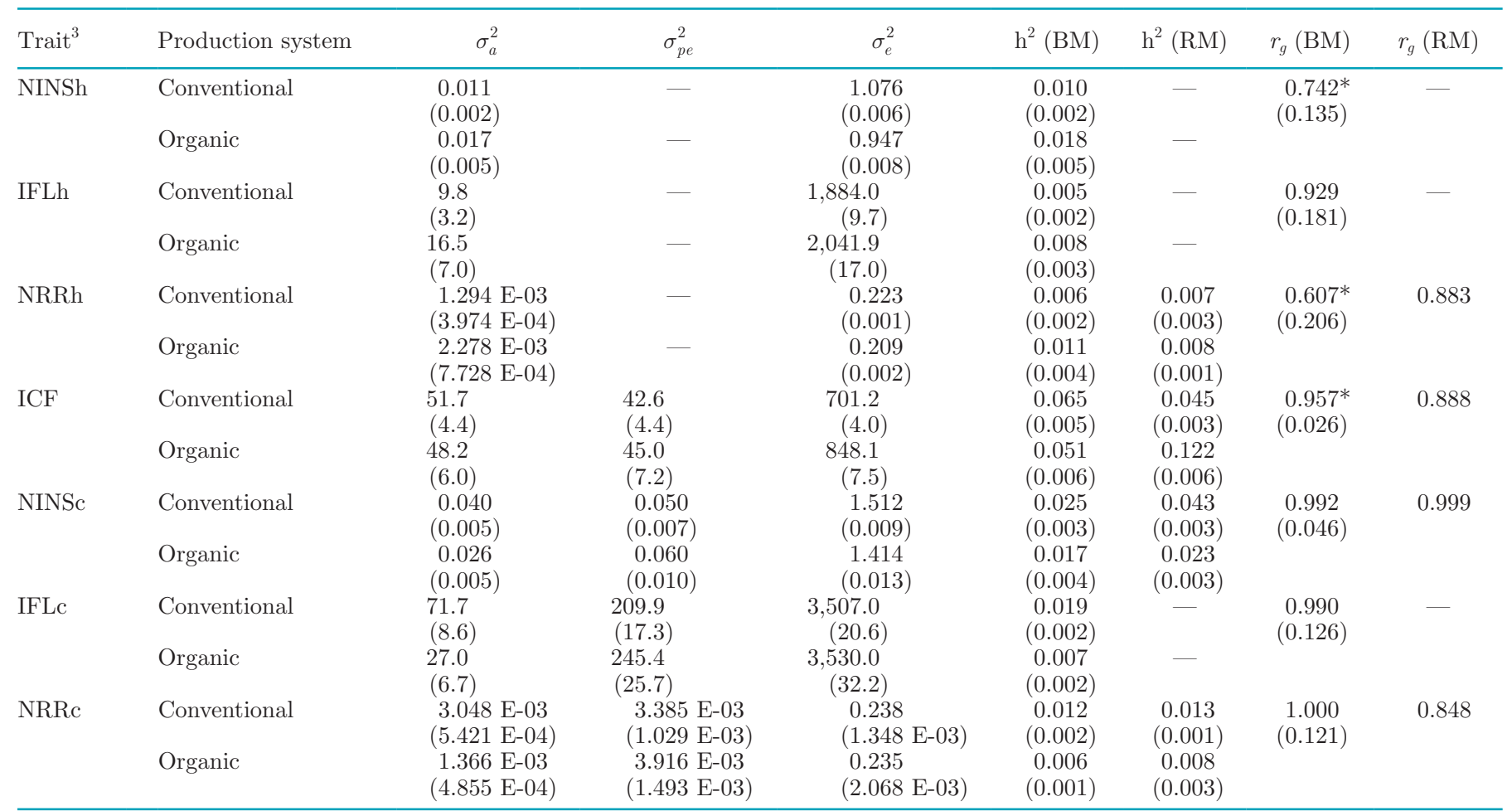

${ }^{1} \sigma_{a}^{2}=$ additive genetic variance; $\sigma_{p e}^{2}=$ permanent environmental variance; $\sigma_{e}^{2}=$ residual variance.

${ }^{2}$ Average grass of feed for the reduced data set was 0.17 for the conventional production system and 0.53 for the organic production system.

${ }^{3} \mathrm{NINS}=$ number of inseminations per conception; IFL $=$ the interval from first to last insemination; NRR $=$ non-return rate within $56 \mathrm{~d}$ after the first insemination; ICF = the interval from calving to first insemination. For the traits both expressed in heifers and cows, a suffix h (for heifers) and or c (for cows) was attached to the trait abbreviation.

$* P<0.05$.

correlations under conventional and organic production systems are presented in Table 2. Estimates of heritabilities for female fertility traits were generally low, ranging from 0.005 for IFLh under the conventional production system to 0.065 for ICF also under the conventional production system. Standard errors for heritabilities ranged from 0.001 to 0.006 , suggesting that all estimated heritabilities were significantly different from zero. Heterogeneities in additive genetic variances and heritabilities were observed under conventional and organic production systems for all traits. Additive genetic variances and heritabilities in the organic production system were higher than those in the conventional production system for heifer traits, whereas these estimates in the conventional production system were higher than those in the organic production system for cow traits. Genetic correlations between organic and conventional production systems ranged from 0.607 for NRRh to 0.992 for NINSc. Standard errors for genetic correlations ranged from 0.026 to 0.206 . Based on the $t$-test for the genetic correlation, statistically significant $G \times E$ were observed for NINSh, NRRh, and ICF, whereas no statistically significant $G \times E$ was observed for IFLh, NINSc, IFLc, and NRRc. For ICF, although a statistically significant $\mathrm{G} \times \mathrm{E}$ was observed, the high genetic correlation (0.957) indicated that $\mathrm{G} \times \mathrm{E}$ had limited influences on EBV and the response to selection.

\section{Reaction Norm Model}

For the reaction norm model, estimates of variance components and genetic correlations across $\mathbf{a}_{0}, \mathbf{a}_{1}$, and $\mathbf{a}_{2}$ are presented in Table 3 . The reaction norm model for IFLh, NINSh, and IFLc did not converge. The $r_{a_{0} a_{1}}$ ranged from -0.925 to -0.459 , the $r_{a_{0} a_{2}}$ ranged from -0.987 to -0.720 , and the $r_{a_{1} a_{2}}$ ranged from 0.597 to 0.972 . The correlations between $\mathbf{a}_{0}, \mathbf{a}_{1}$, and $\mathbf{a}_{2}$ represented overall relationships between these components in the population. In addition, the correlation between the intercept $\left(\mathbf{a}_{0}\right)$ and the slope $\left(\mathbf{a}_{1}\right.$ or $\left.\mathbf{a}_{2}\right)$ had an influence on the degree of $\mathrm{G} \times \mathrm{E}$. For example, for 2 envi- 
ronments with environmental values $\mathrm{x}_{1}$ and $\mathrm{x}_{2}$, the covariance between breeding values of these 2 environments is

$\operatorname{Cov}\left(a_{0}+a_{i} \mathrm{x}_{1}, \quad a_{0}+a_{i} \mathrm{x}_{2}\right)=\sigma_{a_{0}}^{2}+\mathrm{x}_{1} \mathrm{x}_{2} \sigma_{a_{i}}^{2}+\left(\mathrm{x}_{1}+\mathrm{x}_{2}\right) \sigma_{a_{0} a_{i}}$.

In this study, because environmental values of both grass ratio of feed and production systems were positive, the negative correlation between the intercept and the slope $\left(r_{a_{0} a_{1}}\right.$ and $\left.r_{a_{0} a_{2}}\right)$ could increase $\mathrm{G} \times \mathrm{E}$ whereas the positive correlation could decrease $\mathrm{G} \times \mathrm{E}$. Based on the $t$-test for the variance of the slope, statistically significant $\mathrm{G} \times \mathrm{E}$ were observed for ICF and NINSc, whereas no statistically significant $\mathrm{G} \times \mathrm{E}$ was observed for NRRh and NRRc. Similarly, the likelihood ratio test showed that the reaction norm model had significantly better fitness than the reduced model ignoring $\mathrm{G}$ $\times \mathrm{E}$ for ICF and NINSc $(P<0.05)$, but not for NRRh and NRRc $(P>0.05)$.

Given the information of the production system and the grass ratio of feed, heritabilities of any environments and genetic correlations between any 2 environments can be estimated in the reaction norm model. Heritabilities for each production system with the change of grass ratio of feed are presented in Figure 2. It was observed that the patterns of heritabilities with the change of grass ratio of feed were similar across 2 production systems. When increasing the level of grass ratio of feed, heritabilities increased for ICF and decreased for NINSc in both production systems, but no clear pattern was observed for NRRh and NRRc. Genetic correlations between traits measured in conventional herds and organic herds with the same grass ratio of feed depended on the level of grass ratio of feed (see Table 4). When increasing the level of grass ratio of feed, the genetic correlation between traits in the 2 production systems increased for ICF and decreased for NINSc, but no clear trend was observed for NRRh and NRRc. Genetic correlations between traits measured in herds within the same production system but with different grass ratio of feed were also different (see Figure 3 ), depending on differences between grass ratio of feed. For example, for NINSc within the conventional production system, the genetic correlation between a herd with grass ratio of feed at 0.6 and another herd with grass ratio of feed at 0.4 is 0.897 , but the genetic correlation decreased to 0.800 between a herd with grass ratio of feed at 0.6 and another herd with grass ratio of feed at 0.2 .

\section{Comparisons of 2 Models}

For the reduced data set, the average grass ratio of feed was 0.17 for the conventional production system and 0.53 for the organic production system. To compare the results from the reaction norm model with those from the bivariate model, heritabilities with average grass ratio of feed for the reduced data set were calculated (see Table 2). Heritabilities from the reaction norm model ranged from 0.007 for NRRh to 0.122 for ICF. Similar to the results from the bivariate model, heritabilities in the organic production system were higher than those in the conventional production system for heifer traits, whereas these estimates in the conventional production system were higher than those in the organic production system for cow traits, except for ICF. Genetic correlations between the average grass ratio of feed in the conventional production system and the average grass ratio of feed in the organic production system in the reduced data set are presented in Table 2. The genetic correlations from the reaction norm model

Table 3. Variance components ${ }^{1}$ and genetic correlations ${ }^{2}$ from the reaction norm model using the full data set

\begin{tabular}{|c|c|c|c|c|c|c|c|c|}
\hline Trait $^{3}$ & $\sigma_{a_{0}}^{2}$ & $\sigma_{a_{1}}^{2}$ & $\sigma_{a_{2}}^{2}$ & $\sigma_{p e}^{2}$ & $\sigma_{e}^{2}$ & $r_{a_{0} a_{1}}$ & $r_{a_{0} a_{2}}$ & $r_{a_{1} a_{2}}$ \\
\hline NINSc & $\begin{array}{c}0.172 \\
(0.026)\end{array}$ & $\begin{array}{l}8.714 \text { E-03* } \\
(5.076 \text { E-03) }\end{array}$ & $\begin{array}{c}0.192^{*} \\
(0.050)\end{array}$ & $\begin{array}{c}4.437 \text { E-02 } \\
(3.246 \text { E-03) }\end{array}$ & $\begin{array}{c}1.440 \\
(0.003)\end{array}$ & $\begin{array}{c}-0.925 \\
(0.092)\end{array}$ & $\begin{array}{c}-0.987 \\
(0.019)\end{array}$ & $\begin{array}{c}0.972 \\
(0.117)\end{array}$ \\
\hline NRRc & $\begin{array}{c}5.262 \text { E-03 } \\
(2.493 \text { E-03) }\end{array}$ & $\begin{array}{c}9.111 \text { E-04 } \\
(9.572 \text { E-04) }\end{array}$ & $\begin{array}{c}9.604 \text { E-03 } \\
(6.623 \text { E-03) }\end{array}$ & $\begin{array}{c}3.699 \text { E-03 } \\
(4.291 \text { E-04) }\end{array}$ & $\begin{array}{l}0.236 \\
(5.490 \mathrm{E}-04)\end{array}$ & $\begin{array}{c}-0.459 \\
(0.341)\end{array}$ & $\begin{array}{r}-0.789 \\
(0.132)\end{array}$ & $\begin{array}{c}0.597 \\
(0.378)\end{array}$ \\
\hline
\end{tabular}

${ }^{1} \sigma_{a_{0}}^{2}=$ additive genetic variance for the intercept; $\sigma_{a_{1}}^{2}=$ additive genetic variance for the regression coefficient on the production system; $\sigma_{a_{2}}^{2}=$ additive genetic variance for the regression coefficient on the grass ratio of feed; $\sigma_{p e}^{2}=$ permanent environmental variance; $\sigma_{e}^{2}=$ residual variance. ${ }^{2} r_{a_{0} a_{1}}=$ genetic correlation between the intercept and the regression coefficient on the production system; $r_{a_{0} a_{2}}=$ genetic correlation between the intercept and the regression coefficient on the grass ratio of feed; $r_{a_{1} a_{2}}=$ genetic correlation between the regression coefficient on the production system and the regression coefficient on the grass ratio of feed.

${ }^{3} \mathrm{NRRh}=$ non-return rate within $56 \mathrm{~d}$ after the first insemination in heifers; ICF $=$ the interval from calving to first insemination; NINSc $=$ number of inseminations per conception in cows; NRRc $=$ non-return rate within $56 \mathrm{~d}$ after the first insemination in cows.

$* P<0.05$. 
ranged from 0.848 for NRRc to 0.999 for NINSc. For the traits with available results from both bivariate models and reaction norm models (NRRh, ICF, NINSc, and NRRc), 2 models led to similar magnitudes of genetic correlations between conventional and organic production systems. Numbers of sires overlapped among top 50 sires (each sire should have at least 20 daughters in the corresponding production system) between 2
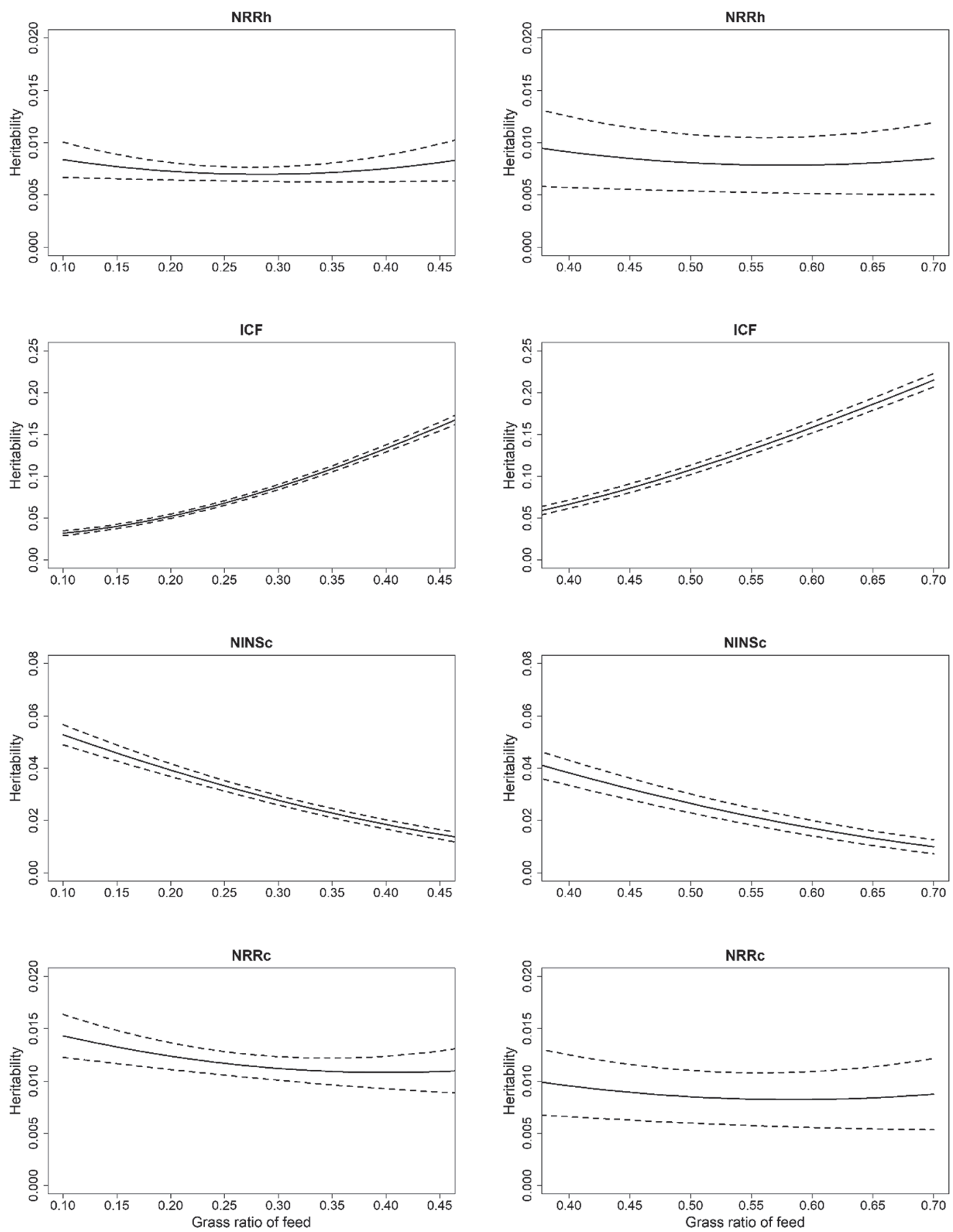

Figure 2. Heritabilities as a function of grass ratio of feed in the range of 95\% interval of grass ratio of feed for conventional (left) and organic (right) production systems, estimated from the reaction norm model using the full data set. The $\mathrm{x}$-axis is the grass ratio of feed, and the $\mathrm{y}$-axis is the heritability. The solid line represents estimates of heritabilities, and dashed lines represent heritabilities $\pm \mathrm{SE}$. NRRh $=$ non-return rate within $56 \mathrm{~d}$ after the first insemination in heifers; ICF $=$ interval from calving to first insemination; NINSc $=$ number of inseminations per conception in cows; NRRc $=$ non-return rate within $56 \mathrm{~d}$ after the first insemination in cows. 
Table 4. Genetic correlations between conventional herds and organic herds with the same grass ratio of feed, estimated from the reaction norm model using the full data set

\begin{tabular}{lccccccc}
\hline Trait $^{1}$ /grass ratio of feed & 0.1 & 0.2 & 0.3 & 0.4 & 0.5 & 0.6 & 0.7 \\
\hline NRRh & 0.852 & 0.793 & 0.732 & 0.694 & 0.698 & 0.740 & 0.798 \\
ICF & 0.645 & 0.765 & 0.908 & 0.964 & 0.983 & 0.991 & 0.994 \\
NINSc & 0.992 & 0.987 & 0.979 & 0.963 & 0.926 & 0.836 & 0.646 \\
NRRc & 0.886 & 0.860 & 0.834 & 0.817 & 0.817 & 0.835 & 0.864 \\
\hline
\end{tabular}

${ }^{1} \mathrm{NRRh}=$ non-return rate within $56 \mathrm{~d}$ after the first insemination in heifers; ICF $=$ the interval from calving to first insemination; NINSc $=$ number of inseminations per conception in cows; NRRc $=$ non-return rate within $56 \mathrm{~d}$ after the first insemination in cows.

environments are presented in Table 5 . For a bivariate model, high re-ranking between 2 production systems was observed for NINSh and NRRh, which had genetic correlations below 0.8 . For a reaction norm model, re-ranking within a production system with extreme grass ratio of feed (5th vs. 95th percentiles) had similar magnitudes of re-ranking as that between 2 production systems with average grass ratio of feed.

\section{DISCUSSION}

\section{Performance of Female Fertility}

All female fertility performances of the organic production system were superior to those of the conventional production system, which was in agreement of previous studies for UK Holstein cows (Pryce et al., 1999). Cows in the conventional production system had higher milk yield than cows in the organic production system (Slagboom et al., 2016), which could lead to worse female fertility for cows in the conventional production system than cows in the organic production system.

\section{Heterogeneities in Heritabilities}

Estimates of heritabilities for female fertility were generally low for both conventional and organic production systems. Low heritabilities for female fertility have been well documented in various populations (Veerkamp and Beerda, 2007; Liu et al., 2017). In this study, heterogeneities in heritabilities under conventional and organic production systems were observed for all traits from both models. In a previous study for Danish Holsteins, heterogeneities of additive genetic variances across production levels were observed for activity-based estrus traits, which were novel female fertility traits with moderate heritabilities (from 0.12 to 0.18) (Ismael et al., 2016). In Australian Holsteins, heritabilities of ICF decreased with the increase of production levels (Haile-Mariam et al., 2008). In UK Holsteins, slightly higher heritabilities were observed for ICF and calving interval in a lower production level
(Strandberg et al., 2009). Although heterogeneities in heritabilities were observed from different analyses, patterns of heritabilities with the change of environments were inconsistent in different studies. This could be caused by different environmental descriptors being used in different studies and limited detection powers resulting from low heritabilities and small sample sizes. Heterogeneities in heritabilities indicated that genetic evaluation based on data from both production systems required a model able to handle the heterogeneities. For example, heterogeneities in variances could be accounted for by using a multiplicative mixed model that scales the heterogeneous variances by introducing heterogeneity factors during the estimation of breeding values (Meuwissen et al., 1996).

\section{Existence and Scope of $G \times E$}

The existence of $\mathrm{G} \times \mathrm{E}$ for female fertility from the 2 models was not the same. This could be due to relatively large standard errors of estimates (the genetic correlation of the bivariate model and the variance of the slope of the reaction norm model), resulting from low heritable nature of female fertility and a small data set of the organic production system. Meanwhile, in the bivariate model, we only kept a subset of conventional herds, which reduced the data size of conventional herds and represented the conventional herds with low grass ratio of feed only. To test the influence of thresholds of grass ratio of feed on the estimation of $\mathrm{G} \times \mathrm{E}$, the bivariate model was also applied to the full data set (see Supplemental Table S1; https://doi .org/10.3168/jds.2018-15482). Compared with results from using the reduced data set, slightly higher genetic correlations and lower standard errors of genetic correlations were observed when using the full data set. The slightly higher genetic correlations from using the full data set than using the reduced data set was due to conventional and organic production systems had fewer differences in grass ratio of feed in the full data set than in the reduced data set. The slightly lower standard errors of genetic correlations from using the full data set than using the reduced data set was due to a 
NRRh

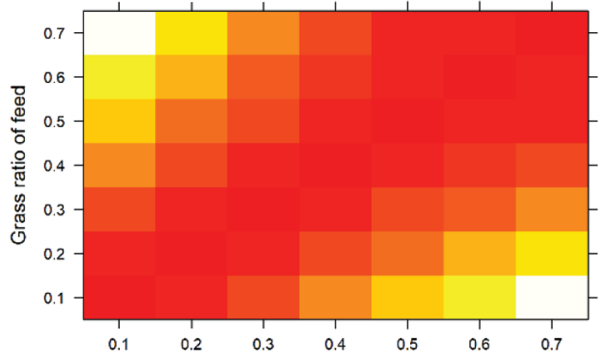

ICF

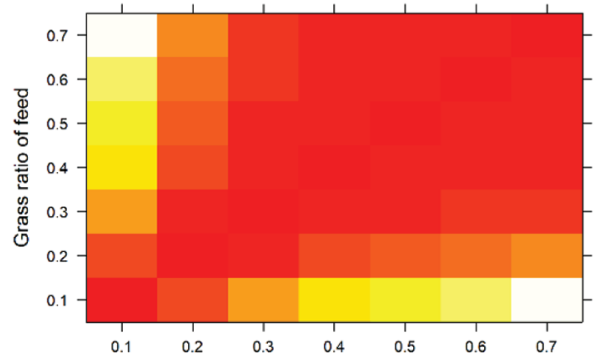

NINSc

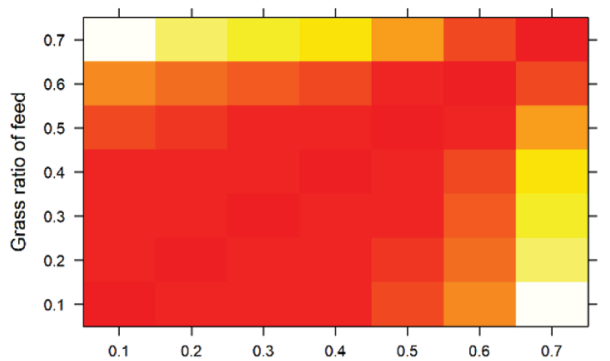

NRRc

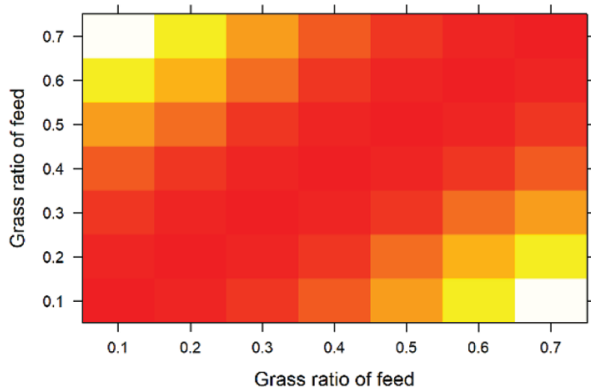

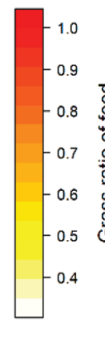

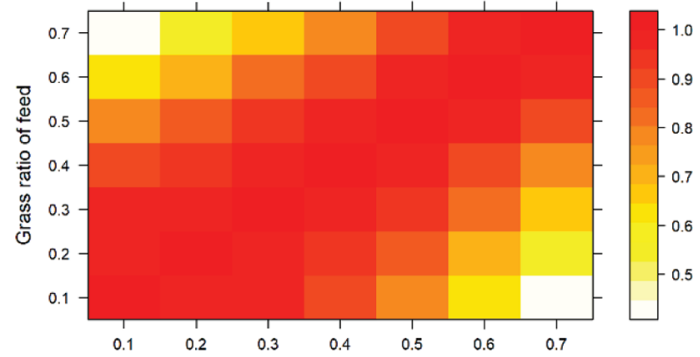

ICF
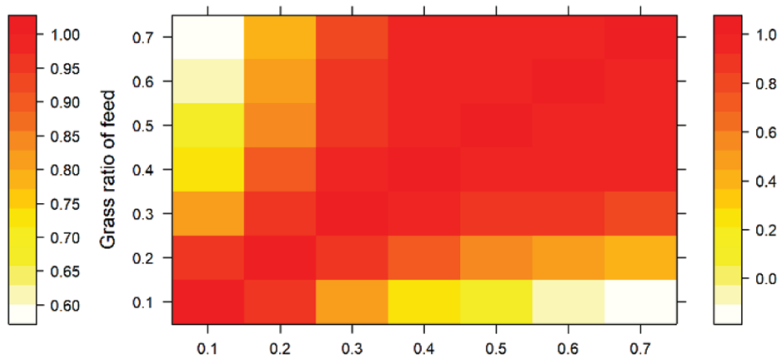

NINSc
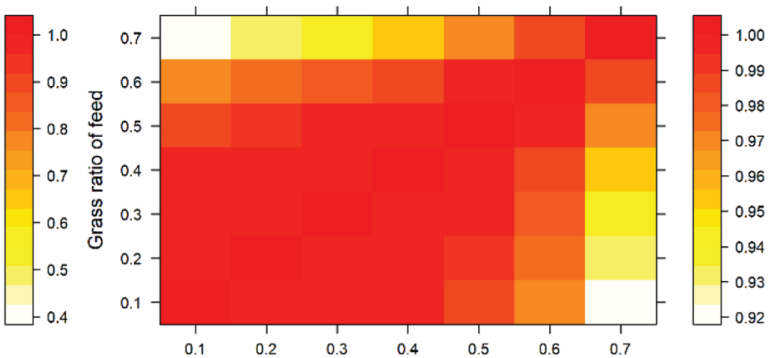

NRRC
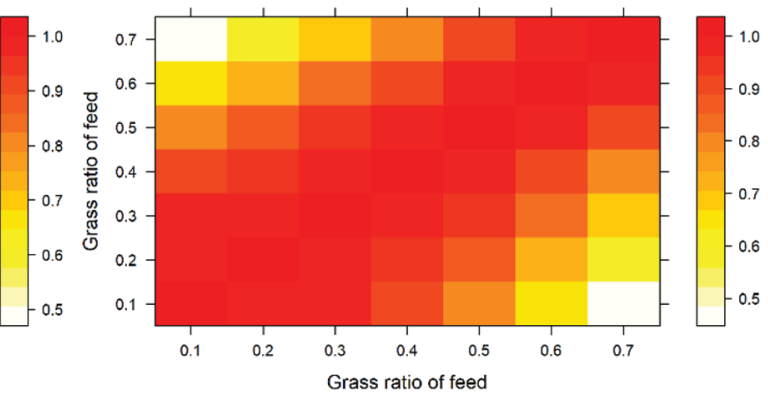

Figure 3. Genetic correlations between herds with different grass ratio of feed for conventional (left) and organic (right) production systems, estimated from the reaction norm model using the full data set. NRRh $=$ non-return rate within $56 \mathrm{~d}$ after the first insemination in heifers; ICF $=$ interval from calving to first insemination; NINSc $=$ number of inseminations per conception in cows; NRRc $=$ non-return rate within $56 \mathrm{~d}$ after the first insemination in cows.

much larger sample size of the conventional production system in the full data set than in the reduced data set.

The conventional production system usually represents an intensive farming mode, whereas the organic production system usually represents an extensive farming mode. In Denmark, however, organic herds had similar herd sizes and nearly the same milk yield as conventional herds. Therefore, $\mathrm{G} \times \mathrm{E}$ under conventional 
and organic production systems in countries with more differences between the 2 production systems could be stronger than those observed in Denmark. In Swedish Holsteins, statistically significant $\mathrm{G} \times \mathrm{E}$ under conventional and organic production systems were observed for calving interval $\left(r_{g}=0.64\right)$, days open $\left(r_{g}=0.72\right)$, and conception rate at first insemination $\left(r_{g}=0.54\right)$ in the second lactation; whereas no $\mathrm{G} \times \mathrm{E}$ was observed for these 3 traits in the first lactation and for ICF, IFL, and NINS in both first and second lactations $\left(r_{g}\right.$ ranged from 0.71 for conception rate at first insemination to 1.00 for ICF in the second lactation; Sundberg et al., 2010). In Canadian Holsteins, the genetic correlation was 0.64 for calving interval between pasture-based and conventional production systems, but no statistically significant $\mathrm{G} \times \mathrm{E}$ was observed due to the large standard error (Boettcher et al., 2003). In Australian Holsteins, the genetic correlations were as low as 0.5 for some female fertility traits between the 5th and 95th percentiles of environmental descriptors such as the herd size and the average herd milk production (Haile-Mariam et al., 2008). In US Holsteins, genetic correlations under grazing and confinement herds for days open, ICF, and NINSc were close to unity (Kearney et al., 2004). In UK Holsteins, $\mathrm{G} \times \mathrm{E}$ were observed for IFL and calving interval with respect to the herd average of that trait using the reaction norm model, whereas no $\mathrm{G} \times \mathrm{E}$ was observed for IFL and calving interval using a multivariate model and no $\mathrm{G} \times \mathrm{E}$ for
NINS and NRR using both a reaction norm model and a multivariate model (Strandberg et al., 2009). In Dutch Holsteins, using multivariate models, moderate $\mathrm{G} \times \mathrm{E}$ were observed for milk yield $\left(r_{g}\right.$ ranged from 0.71 to 0.88 ), whereas no $\mathrm{G} \times \mathrm{E}$ was observed for fat percentage, protein percentage, and mastitis $\left(r_{g}\right.$ close to unity; Nauta et al., 2006).

\section{Statistical Models for Estimating $G \times E$}

The bivariate model treated performances of a trait in conventional and organic production systems as different traits. The reaction norm model allowed that each genotype had a unique reaction pattern of performance to the environment descriptor. One advantage of the reaction norm model over the bivariate model was that the reaction norm model could handle the continuous environmental levels. However, when the data are less informative, the reaction norm model could be difficult to converge caused by the complexity of the model. A previous study for comparisons between a multivariate model and a reaction norm model showed that benefits of using a reaction norm model were dependent on the environmental descriptor used (Calus et al., 2002).

The feeding level was highly recommended as an environmental descriptor to model $\mathrm{G} \times \mathrm{E}$ across multiple production systems in previous studies (Calus et al., 2002; Fikse et al., 2003). Furthermore, low correlations across multiple environmental descriptors were pre-

Table 5. The number of sires overlapped between top 50 sires $^{1}$ in 2 environments, estimated from the bivariate model (BM) using the reduced data set and the reaction norm model (RM) using the full data set

\begin{tabular}{|c|c|c|c|c|}
\hline \multirow[b]{2}{*}{ Trait $^{2}$} & \multirow[b]{2}{*}{$\begin{array}{l}\text { Conventional vs. } \\
\text { organic }(\mathrm{BM})^{3}\end{array}$} & \multirow[b]{2}{*}{$\begin{array}{l}\text { Conventional vs. } \\
\text { organic }(\mathrm{RM})^{4}\end{array}$} & \multicolumn{2}{|c|}{$\begin{array}{c}\text { 5th vs. 95th percentiles of grass ratio } \\
\text { of feed (RM) }\end{array}$} \\
\hline & & & Conventional $^{5}$ & Organic $^{6}$ \\
\hline NINSh & 25 & - & - & - \\
\hline IFLh & 44 & - & - & - \\
\hline NRRh & 19 & 43 & 42 & 42 \\
\hline ICF & 46 & 39 & 38 & 41 \\
\hline NINSc & 41 & 49 & 47 & 47 \\
\hline IFLc & 50 & - & - & - \\
\hline NRRc & 49 & 47 & 46 & 46 \\
\hline
\end{tabular}

${ }^{1}$ Each sire should have at least 20 daughters in the corresponding production system.

${ }^{2}$ NINS $=$ number of inseminations per conception; IFL $=$ interval from first to last insemination; NRR $=$ non-return rate within $56 \mathrm{~d}$ after the first insemination; ICF $=$ interval from calving to first insemination. For the traits both expressed in heifers and cows, a suffix $\mathrm{h}$ (for heifers) or c (for cows) was attached to the trait abbreviation.

${ }^{3}$ Overlaps between top sires in conventional and organic production systems, estimated from a bivariate model. ${ }^{4}$ Overlaps between top sires in conventional and organic production systems with average grass ratio of feed (for the reduced data set), estimated from a reaction norm model. Average grass ratio of feed for the reduced data set was 0.17 for the conventional production system and 0.53 for the organic production system.

${ }^{5}$ Overlaps between top sires within the conventional production system with 5 th and 95 th percentiles of grass ratio of feed, estimated from a reaction norm model.

${ }^{6}$ Overlaps between top sires within organic production system with 5th and 95th percentiles of grass ratio of feed, estimated from a reaction norm model. 
ferred when multiple environmental descriptors were used simultaneously (Fikse et al., 2003). In this study, however, moderate to high genetic correlations $\left(r_{a_{1} a_{2}}\right)$, ranging from 0.597 to 0.972 , were observed between the production system and the grass ratios of feed, which could be caused by phenotypes reacting similarly regarding the change of the production system and the grass ratio of feed. This could be a possible reason for the difficulties to converge for some traits.

The same reaction norm pattern of additive genetic effects in relation to grass ratio of feed was considered for conventional and organic production systems. To test whether the patterns of reaction norms of additive genetic effects for grass ratio of feed were consistent across 2 production systems, reaction norm models with random regressions on the grass ratio of feed were performed within each production system (results not shown). Similar patterns of reaction norms of additive genetic effects against grass ratio of feed were observed for conventional and organic production systems, except for ICF. For ICF, ignoring the differences between 2 production systems in the patterns of reaction norms on grass ratio of feed could be the reason that the heritability of the organic production system estimated from the reaction norm model was much higher than that estimated from the bivariate model.

\section{Influences of $G \times E$ on Breeding Programs}

In the current Danish dairy industry, the breeding bulls used for the organic production system are selected based on data from all herds (Kargo et al., 2018), with the majority being from the conventional production system. The possible $\mathrm{G} \times \mathrm{E}$ between 2 production systems has not yet been considered in routine genetic evaluations and breeding programs. Heterogeneities of additive genetic variances and heritabilities were observed between conventional and organic production systems from both models, which would reduce selection accuracy if a prediction model ignores the heterogeneous variances. Furthermore, re-ranking of top sires were observed between 2 production systems as well as within the same production system but with different grass ratio of feed. However, genetic correlations between 2 production systems were above 0.61 for all female fertility traits, which indicated that a single breeding program was still optimal from a response to selection perspective (Mulder et al., 2006). Considerations other than the response to selection such as different breeding goals and no use of reproduction technology (Kargo et al., 2018) could justify separate breeding programs for 2 production systems.

\section{CONCLUSIONS}

All female fertility performances of the organic production system were superior to those of the conventional production system. Besides, heterogeneities in additive genetic variances and heritabilities were observed under conventional and organic production systems for all traits. Furthermore, genetic correlations between these 2 production systems ranged from 0.607 to 1.000 estimated from bivariate models and from 0.848 to 0.999 estimated from reaction norm models. Based on the small $\mathrm{G} \times \mathrm{E}$ detected for female fertility traits, a single breeding program is still optimal from a response to selection perspective, but considerations other than the response to selection such as different breeding goals and no use of reproduction technology could justify separate breeding programs for organic and conventional production systems.

\section{ACKNOWLEDGMENTS}

We greatly appreciate the editor and reviewers for the careful work and valuable comments, which were very helpful for improving the manuscript. This work was financially supported by Milk Production Levy Fund and the Fund for Organic Farming. We thank SEGES (Aarhus, Denmark), the Danish Cattle Federation (Aarhus, Denmark), and Nordic Cattle Genetic Evaluation (Aarhus, Denmark) for providing phenotype and pedigree data of Nordic Holsteins. We thank Ulrik Sander Nielsen (SEGES, Aarhus, Denmark) for help on preparing data. We thank Xiaowei Mao (Cornell University, Ithaca, NY) for nice discussions during the data analyses and for revising the paper. We thank Per Madsen (Aarhus University, Aarhus, Denmark), Lu Cao (Aarhus University), and Line Hjortø (Aarhus University) for nice suggestions during data analyses. The first author acknowledges the scholarship provided by the China Scholarship Council (CSC).

\section{REFERENCES}

Bennedsgaard, T. W., S. M. Thamsborg, M. Vaarst, and C. Enevoldsen. 2003. Eleven years of organic dairy production in Denmark: Herd health and production related to time of conversion and compared to conventional production. Livest. Prod. Sci. 80:121-131.

Boelling, D., A. F. Groen, P. Sørensen, P. Madsen, and J. Jensen. 2003. Genetic improvement of livestock for organic farming systems. Livest. Prod. Sci. 80:79-88.

Boettcher, P. J., J. Fatehi, and M. M. Schutz. 2003. Genotype × environment interactions in conventional versus pasture-based dairies in Canada. J. Dairy Sci. 86:383-389.

Calus, M. P. L., A. F. Groen, and G. De Jong. 2002. Genotype × environment interaction for protein yield in Dutch dairy cattle as quantified by different models. J. Dairy Sci. 85:3115-3123. 
Calus, M. P. L., J. J. Windig, and R. F. Veerkamp. 2005. Associations among descriptors of herd management and phenotypic and genetic levels of health and fertility. J. Dairy Sci. 88:2178-2189.

Cardoso, F. F., and R. J. Tempelman. 2012. Linear reaction norm models for genetic merit prediction of Angus cattle under genotype by environment interaction. J. Anim. Sci. 90:2130-2141.

Falconer, D. S., and T. F. C. Mackay. 1996. Introduction to Quantitative Genetics. 4th ed. Longman Group, Essex, UK.

Fikse, W. F., R. Rekaya, and K. A. Weigel. 2003. Assessment of environmental descriptors for studying genotype by environment interaction. Livest. Prod. Sci. 82:223-231.

Fischer, T. M., A. R. Gilmour, and J. H. van der Werf. 2004. Computing approximate standard errors for genetic parameters derived from random regression models fitted by average information REML. Genet. Sel. Evol. 36:363.

González-Recio, O., M. A. Perez-Cabal, and R. Alenda. 2004. Economic value of female fertility and its relationship with profit in Spanish dairy cattle. J. Dairy Sci. 87:3053-3061.

Haile-Mariam, M., M. J. Carrick, and M. E. Goddard. 2008. Genotype by environment interaction for fertility, survival, and milk production traits in Australian dairy cattle. J. Dairy Sci. 91:4840-4853.

Interbull. 2018. MACE Evaluations Archive. Accessed Feb. 25, 2019. http://www.interbull.org/ib/maceev_archive.

Ismael, A., E. Strandberg, B. Berglund, M. Kargo, A. Fogh, and P. Løvendahl. 2016. Genotype by environment interaction for activity-based estrus traits in relation to production level for Danish Holstein. J. Dairy Sci. 99:9834-9844.

Kargo, M., L. Hjortø, M. Toivonen, J. A. Eriksson, G. P. Aamand, and J. Pedersen. 2014. Economic basis for the Nordic Total Merit index. J. Dairy Sci. 97:7879-7888.

Kargo, M., P. Madsen, and E. Norberg. 2012. Is crossbreeding only beneficial in herds with low management level? J. Dairy Sci. 95:925-928.

Kargo, M., J. R. Thomasen, A. Wallenbeck, L. Hjortø, and M. Slagboom. 2018. Organic dairy breeding lines? - Possibilities and requirements. Proceedings of the World Congress on Genetics Applied to Livestock Production, Vol. Genetic Gain - Breeding Strategies 1:536.

Kearney, J. F., M. M. Schutz, and P. J. Boettcher. 2004. Genotypex environment interaction for grazing vs. confinement. II. Health and reproduction traits. J. Dairy Sci. 87:510-516.

Kolmodin, R., E. Strandberg, P. Madsen, J. Jensen, and H. Jorjani. 2002. Genotype by environment interaction in Nordic dairy cattle studied using reaction norms. Acta Agric. Scand. A Anim. Sci. $52: 11-24$.

Lauridsen, U. 2018. Personal communication based on statistics on monthly performance of Danish dairy cows under yield registration. Accessed Jan. 31, 2018. https://www.landbrugsinfo.dk/ kvaeg/tal-om-kvaeg/sider/mndstatmain.aspx.

Liu, A., M. S. Lund, Y. Wang, G. Guo, G. Dong, P. Madsen, and G. Su. 2017. Variance components and correlations of female fertility traits in Chinese Holstein population. J. Anim. Sci. Biotechnol. 8:e56.

Madsen, P., and J. Jensen. 2012. A User's Guide to DMU, Version 6 release 5.1. Faculty of Agricultural Sciences, Aarhus University, Aarhus, Denmark.

Meuwissen, T. H. E., G. de Jong, and B. Engel. 1996. Joint estimation of breeding values and heterogeneous variances of large data files. J. Dairy Sci. 79:310-316.
Mulder, H. A., R. F. Veerkamp, B. J. Ducro, J. A. M. van Arendonk, and P. Bijma. 2006. Optimization of dairy cattle breeding programs for different environments with genotype by environment interaction. J. Dairy Sci. 89:1740-1752.

Nauta, W. J., R. F. Veerkamp, E. W. Brascamp, and H. Bovenhuis. 2006. Genotype by environment interaction for milk production traits between organic and conventional dairy cattle production in the Netherlands. J. Dairy Sci. 89:2729-2737.

NAV. 2018. NAV routine genetic evaluation of dairy cattle - Data and genetic models. Accessed Jun. 7, 2019. https://www.nordicebv .info/wp-content/uploads/2019/02/NAV-routine-genetic -evaluation-2019.pdf.

Oliveira, D. P., D. A. L. Lourenco, S. Tsuruta, I. Misztal, D. J. A. Santos, F. R. de Araújo Neto, R. R. Aspilcueta-Borquis, F. Baldi, R. Carvalheiro, G. M. F. de Camargo, and L. G. Albuquerque. 2018. Reaction norm for yearling weight in beef cattle using single-step genomic evaluation. J. Anim. Sci. 96:27-34

Pryce, J. E., B. L. Nielsen, R. F. Veerkamp, and G. Simm. 1999 Genotype and feeding system effects and interactions for health and fertility traits in dairy cattle. Livest. Prod. Sci. 57:193-201.

Rosati, A., and A. Aumaitre. 2004. Organic dairy farming in Europe. Livest. Prod. Sci. 90:41-51.

Slagboom, M., M. Kargo, D. Edwards, A. C. Sørensen, J. R. Thomasen, and L. Hjortø. 2016. Organic dairy farmers put more emphasis on production traits than conventional farmers. J. Dairy Sci. 99:9845-9856.

Strandberg, E., S. Brotherstone, E. Wall, and M. P. Coffey. 2009. Genotype by environment interaction for first-lactation female fertility traits in UK dairy cattle. J. Dairy Sci. 92:3437-3446.

Strandberg, E., R. Kolmodin, P. Madsen, J. Jesnsen, and H. Jorjani. 2000. Genotype by environment interaction in Nordic Dairy Cattle studied by use of reaction norms. Pages 41-45 in Proc. 2000 Interbull meeting, Bled, Slovenia.

Su, G., M. S. Lund, and D. Sorensen. 2007. Selection for litter size at day five to improve litter size at weaning and piglet survival rate. J. Anim. Sci. 85:1385-1392.

Su, G., P. Madsen, M. S. Lund, D. Sorensen, I. R. Korsgaard, and J. Jensen. 2006. Bayesian analysis of the linear reaction norm model with unknown covariates. J. Anim. Sci. 84:1651-1657.

Sundberg, T., L. Rydhmer, W. F. Fikse, B. Berglund, and E. Strandberg. 2010. Genotype by environment interaction of Swedish dairy cows in organic and conventional production systems. Acta Agric. Scand. A Anim. Sci. 60:65-73.

Thøgersen, J., S. Pedersen, M. Paternoga, E. Schwendel, and J. Aschemann-Witzel. 2017. How important is country-of-origin for organic food consumers? A review of the literature and suggestions for future research. Br. Food J. 119:542-557.

Veerkamp, R. F., and B. Beerda. 2007. Genetics and genomics to improve fertility in high producing dairy cows. Theriogenology 68:S266-S273.

Von Borell, E., and J. T. Sørensen. 2004. Organic livestock production in Europe: Aims, rules and trends with special emphasis on animal health and welfare. Livest. Prod. Sci. 90:3-9.

Windig, J. J., H. A. Mulder, D. I. Bohthe-Wilhelmus, and R. F Veerkamp. 2011. Simultaneous estimation of genotype by environment interaction accounting for discrete and continuous environmental descriptors in Irish dairy cattle. J. Dairy Sci. 94:3137-3147. 